\title{
Surgical correction of nasal obstruction in the treatment of mild sleep apnoea: importance of cephalometry in predicting outcome
}

\author{
F Sériès, S St Pierre, G Carrier
}

\begin{abstract}
Background-A study was undertaken to determine if cephalometric radiographs could identify those who will benefit from nasal surgery in patients with a sleep apnoea hypopnoea syndrome (SAHS) and chronic nasal obstruction.
\end{abstract}

Methods-Fourteen patients with SAHS were enrolled. Those with normal posterior airway space and mandibular plane to hyoid bone distances on preoperative cephalometric radiographs were matched with those with abnormal cephalometry for the frequency of sleep disordered breathing and body mass index. Polysomnographic studies (all subjects) and nasal resistance measurements (n = 10) were performed one to three months before and two to three months after surgery (septoplasty, turbinectomy, and polypectomy).

Results-There was no difference in the baseline results of the polysomnographic studies between the two groups of patients. Nasal resistance decreased from a mean (SE) value of $2.9(0.3) \mathrm{cm} \mathrm{H}_{2} \mathrm{O} / \mathrm{N} / \mathrm{s}$ before surgery to $1.4(0.1) \mathrm{cm} \mathrm{H}_{2} \mathrm{O} / \mathrm{/s}$ after surgery in the normal cephalometry group and from $2.7(0.3) \mathrm{cm} \mathrm{H}_{2} \mathrm{O} / \mathrm{/s}$ to 1.3 $(0.3) \mathrm{cm} \mathrm{H}_{2} \mathrm{O} / 1 / \mathrm{s}$ in the other group. The apnoea + hypopnoea index returned to normal ( $<10$ breathing abnormalities/ hour) in all but one subject with normal cephalometric measurements, and sleep fragmentation improved with a decrease in the arousal index from $23.9(3 \cdot 3)$ /hour at baseline to $10.6(2.5)$ /hour after surgery. Both of these parameters remained unchanged after surgery in the patients with abnormal cephalometry.

Conclusions-Normal cephalometry is helpful in identifying patients with mild SAHS and nasal obstruction who will benefit from nasal surgery. The presence of craniomandibular abnormalities makes it unlikely that nasal surgery will improve sleep related breathing abnormalities.

(Thorax 1993;48:360-363)

The sleep apnoea hypopnoea syndrome (SAHS) is characterised by recurrent episodes of upper airway obstruction. Of the different factors involved in its pathophysiology, the inspiratory transpharyngeal pressure gradient is thought to have a key role as it represents the collapsing force applied to the pharyngeal tissues. ${ }^{12}$ Since the collapsibility of the upper airways is increased in SAHS, ${ }^{34}$ any increase in the inspiratory pressure gradient can lead to upper airway closure. The increase in nasal resistance that increases this negative pressure may therefore be responsible for the occurrence of sleep related obstructive breathing disorders. This has been confirmed in selected reports where reversible breathing abnormalities were observed during transient episodes of nasal obstruction..$^{5-7}$

In addition to the theoretical benefits of improving nasal ventilation in patients with SAHS, nasal surgery has been reported to be of partial benefit ${ }^{8-10}$ or to be ineffective ${ }^{1011}$ in the treatment of obstructive sleep apnoea. Oropharyngeal structures are commonly abnormal in patients with SAHS; the abnormalities include a decrease in the pharyngeal cross sectional area ${ }^{12-14}$ associated with craniomandibular abnormalities. ${ }^{1516}$ The ineffectiveness of nasal surgery could be related to the presence of these upper airway abnormalities which govern the development of upper airway obstruction during sleep. Cephalometric measurements provide useful information on bony and soft tissue abnormalities of the upper airways, ${ }^{15}$ and on the effectiveness of oropharyngeal surgery. ${ }^{17}$ Recent results obtained in our laboratory suggest that nasal surgery has a limited efficacy in the treatment of adult SAHS ${ }^{18}$ but the study was not designed to evaluate the importance of cephalometry. The aim of this study was to determine whether cephalometry could predict the effectiveness of nasal surgery in patients with the sleep apnoea hypopnoea syndrome.

\section{Methods}

SUBJECTS

The study population comprised 14 patients referred for symptoms suggestive of SAHS (snoring, nocturnal choking, bad sleep quality, diurnal hypersomnolence) who also had symptomatic fixed nasal obstruction. All 14 were documented to have SAHS. Their nasal ventilation was impeded by nasal septum deviation, turbinal hypertrophy, with or without polyps, as assessed by clinical examination 
and rhinopharyngoscopy. No patient was treated for SAHS or nasal obstruction other than by surgery before and during the course of the study. To participate in the study patients with nasal obstruction and SAHS had to be matched for their baseline apnoea + hypopnoea index and body mass index according to the results of cephalometry (see below).

\section{STUDY DESIGN}

Conventional sleep studies were performed one to three months before and two to three months after nasal surgery. Surgery consisted of correcting septum deviation and submucosal resection and turbinectomy in 12 , together with polypectomy in the other two patients. Sleep studies included the recording of sleep stages (electroencephalogram $\mathrm{C}_{4} \mathrm{~A}_{1}$, $\mathrm{C}_{3} \mathrm{~A}_{2}$; electrooculogram; submental electromyogram), measuring airflow at the nose and mouth with thermocouples (Grass Instruments, Quincy, Maryland, USA), arterial oxygen saturation $\left(\mathrm{SaO}_{2}\right)$ with a Criticare 504 ear oximeter (CSI, Waukesha, Wisconsin, USA), electrocardiogram, thoracoabdominal movements measured by respiratory inductive plethysmography (Respitrace, Ambulatory Monitoring, Ardsley, New York, USA) calibrated by the isovolume method, ${ }^{19}$ and in eight patients intrathoracic pressures with an oesophageal balloon. All parameters were recorded on a 16-channel polygraph (Model 78; Grass Instruments, Quincy, Maryland, USA) at a paper speed of $10 \mathrm{~mm} / \mathrm{s}$. Sleep studies were manually interpreted according to standard criteria. ${ }^{20}$ An episode of apnoea was defined as an absence of airflow for at least 10 seconds, and an episode of hypopnoea as a $50 \%$ decrease in the sum signal of the body plethysmography associated with an $\mathrm{SaO}_{2}$ fall greater than $4 \%$. An arousal was defined by the simultaneous transition to a lighter sleep stage with eye movements and increase in electromyographic activity of less than 15 seconds. ${ }^{21}$

The effects of surgery on nasal resistance

Table 1 Individual results of cephalometric measurements obtained at baseline. These values were normal in patients 1 to 7 and abnormal in patients 8 to 14

\begin{tabular}{llllll}
\hline & $S N A()$ & $S N B()$ & $P A S(\mathrm{~mm})$ & $M P H(\mathrm{~mm})$ & $P N S-P(\mathrm{~mm})$ \\
\hline 1 & 75 & 77 & 11 & 15 & 45 \\
2 & 77 & 79 & 11 & 15 & 48 \\
3 & 74 & 73 & 9 & 18 & 35 \\
4 & 85 & 83 & 14 & 16 & 38 \\
5 & 85 & 78 & 12 & 18 & 41 \\
6 & 73 & 75 & 13 & 17 & 40 \\
7 & 79 & 79 & 11 & 22 & 44 \\
Mean (SD) & $78 \cdot 3(4 \cdot 9)$ & $77 \cdot 7(3 \cdot 2)$ & $11 \cdot 6(1 \cdot 6)$ & $17 \cdot 3(2 \cdot 4)$ & $41 \cdot 6(4 \cdot 4)$ \\
8 & 72 & 68 & 6 & 36 & 45 \\
9 & 81 & 75 & 7 & 37 & 44 \\
10 & 79 & 76 & 5 & 24 & 45 \\
11 & 86 & 82 & 6 & 36 & 41 \\
12 & 82 & 79 & 11 & 25 & 41 \\
13 & 87 & 81 & 7 & 37 & 40 \\
14 & 80 & 74 & 9 & 28 & 41 \\
Mean (SD) & $81 \cdot 0(4 \cdot 9)$ & $76 \cdot 4(4 \cdot 8)$ & $7 \cdot 3(2 \cdot 0)$ & $31 \cdot 8(5 \cdot 9)$ & $42 \cdot 4(2 \cdot 1)$ \\
\hline
\end{tabular}

SNA-angle from sella to nasion to subspinale; SNB-angle from sella to nasion to supramentale; PAS-posterior airway space; PNS-P-length of the soft palate; $\mathrm{MP}-\mathrm{H}-$ mandibular plane to the hyoid bone. were assessed in 10 of the 14 patients, the four others refusing the procedure. Nasal resistance was measured without local anaesthesia in the supine position at 08.00 on the morning after the sleep studies as previously described.22 Briefly, a low bias flow catheter was introduced into one nostril, its tip positioned just above the uvula. The subjects breathed through a tightly fitted facemask connected to a pneumotachograph. The resistance of the breathing circuit was $0.8 \mathrm{~cm}$ $\mathrm{H}_{2} \mathrm{O} / \mathrm{l} / \mathrm{s}$. Inspiratory resistance was determined at isoflow $(300 \mathrm{ml} / \mathrm{s})$ during one minute of nasal breathing. In our laboratory the normal nasal resistance value with this method is 1.2 $(0 \cdot 1) \mathrm{cm} \mathrm{H}_{2} \mathrm{O} / \mathrm{l} / \mathrm{s}$.

Conventional lateral cephalometric radiographs ${ }^{23}$ were obtained and interpreted before surgery. Standard landmarks were measured by the same investigator (GC) to determine the angle from sella to nasion to subspinale (SNA), the angle from sella to nasion to supramentale (SNB), the distance from the posterior margin of the tongue to the pharyngeal posterior wall (posterior airway space (PAS)), the length of the soft palate (PNS-P), and the distance from the mandibular plane to the hyoid bone (MP-H). In the age range of our patients, mean (SD) normal values obtained in our laboratory are: SNA, $83(2)^{\circ}$; SNB, 80 (2) ${ }^{\circ}$; PAS, 11 (2) mm; MP-H, 19 (2) $\mathrm{mm}$; PNS-P, 39 (4) $\mathrm{mm}$.

Patients with mean (2 SD) normal PAS and $\mathrm{MP}-\mathrm{H}$ measurements were matched to those with abnormal values of these variables for body mass index (BMI) and apnoea + hypopnoea index. The PAS and MP-H distances were used because they are the predominant variables that help to determine the respiratory disturbance indices ${ }^{15}$ and the success of pharyngeal surgery. ${ }^{17}$

\section{STATISTICAL ANALYSIS}

For each variable we first verified that no difference existed between the two groups before surgery. If this hypothesis was not rejected, we sought a significant difference after surgery between the two groups (conditional Hotelling test). ${ }^{24}$ The exact threshold of significance of the sequential procedure was $\mathrm{p}=$ 0.025 as determined from the number of tests performed during this procedure $(n=2)$, taking into account that the different variables were independent.

\section{Results}

Fourteen subjects (12 men and two women) with an age range of $30-58$ years and mean (SE) BMI of $29.4(0.7) \mathrm{kg} / \mathrm{m}^{2}$ participated in the study. The individual results of the cephalometric measurements are reported in table 1. In the group with abnormal cephalometry, abnormalities included an increase in the MP-H distance in all seven and a decrease in the PAS distance in four. A retroposition of the mandible was also noted in four. This last feature was observed in one patient of the group with normal MP-H and PAS values. There were no differences in the 
Table 2 Mean (SE) results of the sleep studies obtained before (baseline) and after nasal surgery

\begin{tabular}{|c|c|c|c|c|}
\hline \multirow[b]{2}{*}{ Cephalometry } & \multicolumn{2}{|l|}{ Baseline } & \multicolumn{2}{|l|}{ After surgery } \\
\hline & Normal & Abnormal & Normal & Abnormal \\
\hline Age (y) & $50(4)$ & $51(2)$ & & \\
\hline Body mass index $\left(\mathrm{kg} / \mathrm{m}^{2}\right)$ & $29 \cdot 5(1.0)$ & $29 \cdot 3(1 \cdot 2)$ & $28.9(1.4)$ & $30 \cdot 4(1 \cdot 3)$ \\
\hline Sleep period time (h) & $6.9(0.4)$ & $7 \cdot 0(0 \cdot 2)$ & $7 \cdot 0(0.5)$ & $7.5(0.2)$ \\
\hline Total sleep time $(\mathrm{h})$ & $5 \cdot 6(0.4)$ & $6 \cdot 1(0.3)$ & $6.1(0.4)$ & $6.9(0.2)$ \\
\hline Sleep efficiency (\%) & $78(4)$ & $80(3)$ & $84(4)$ & $87(2)$ \\
\hline \multicolumn{5}{|l|}{ Sleep stages shift index } \\
\hline (no/h TST) & $20 \cdot 1(2 \cdot 8)$ & $19 \cdot 8(4 \cdot 3)$ & $12.9(1.9)^{\star}$ & $26 \cdot 3(6 \cdot 2)$ \\
\hline Arousals (no/h TST) & $23.9(3.3)$ & $26 \cdot 3(2 \cdot 9)$ & $10 \cdot 6(2 \cdot 5)^{\star}$ & $25 \cdot 0(2 \cdot 6)$ \\
\hline Stage $1-2(\%$ TST $)$ & $67 \cdot 2(3 \cdot 8)$ & $68 \cdot 3(4 \cdot 3)$ & $63 \cdot 2(4 \cdot 6)$ & $68.9(6.2)$ \\
\hline Stage 3-4 (\% TST) & $18 \cdot 2(2 \cdot 6)$ & $16 \cdot 4(2 \cdot 6)$ & $19 \cdot 6(4 \cdot 0)$ & $16 \cdot 3(3.9)$ \\
\hline Stage REM (\% TST) & $14 \cdot 4(2 \cdot 2)$ & $15 \cdot 3(2 \cdot 6)$ & $17 \cdot 2(2 \cdot 1)$ & $14 \cdot 7(2 \cdot 6)$ \\
\hline \multicolumn{5}{|l|}{ Apnoea + hypopnoea } \\
\hline index (no/h TST) & $17 \cdot 0(1 \cdot 3)$ & $18 \cdot 5(1 \cdot 7)$ & $6.5(1 \cdot 0)^{\star}$ & $25.4(2.9)$ \\
\hline Total apnoea time (\% TST) & $7 \cdot 9(1 \cdot 1)$ & $8.9(1.4)$ & $2 \cdot 2(0 \cdot 2)^{\star}$ & $13.9(1.4)$ \\
\hline
\end{tabular}

TST-total sleep time. ${ }^{\star} \mathrm{p}<\theta \cdot 025$ between the two groups at each visit.

anthropometric characteristics of the patients in the two groups nor in the results of the baseline polysomnographic study (table 2). Body weight remained unchanged after surgery. Each patient felt a dramatic improvement in his nasal ventilation and a similar decrease in nasal resistance was seen in each group (from $2.9(0.3) \mathrm{cm} \mathrm{H}_{2} \mathrm{O} / \mathrm{l} / \mathrm{s}$ to $1.4(0.1)$ in the normal cephalometry group and from $2.7(0.3) \mathrm{cm} \mathrm{H}_{2} \mathrm{O} / 1 / \mathrm{s}$ to $1.3(0.3) \mathrm{cm} \mathrm{H}_{2} \mathrm{O} / \mathrm{l} / \mathrm{s}$ in the other group) after surgery (fig 1). No significant difference in sleep architecture was seen between the two groups after surgery, but sleep fragmentation, estimated by the number of arousals, was significantly lower in the normal than in the abnormal cephalometry group (table 2). The frequency of breathing abnormalities (apnoea + hypopnoea index) returned to normal values $(<10$ breathing abnormalities/hour) in all but one of the normal cephalometry group and remained unchanged in all those who had abnormal PAS and MP-H distances (fig 2). This index and the total apnoea time (percentage of total sleep time spent in apnoea) were significantly lower after surgery in the normal cephalometry group (table 2 ).

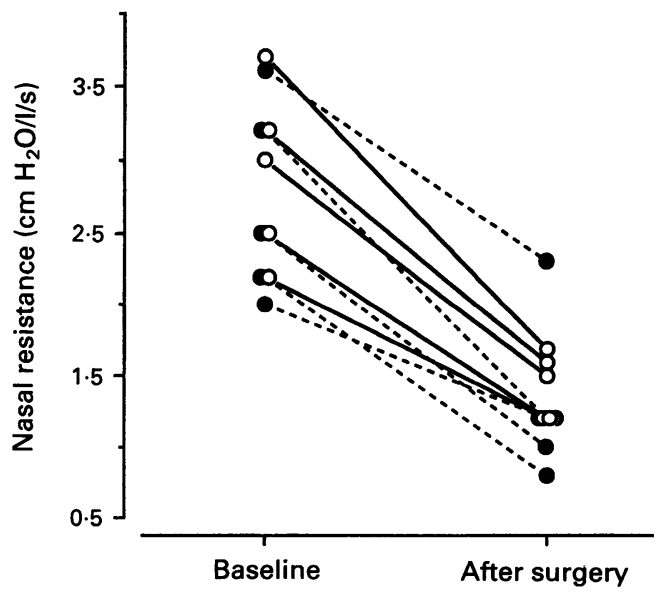
Figure 1 Individual nasal resistance values obtained
before (baseline) and after nasal surgery in the patients with normal (open circles) and abnormal (black circles) cephalometric measurements.

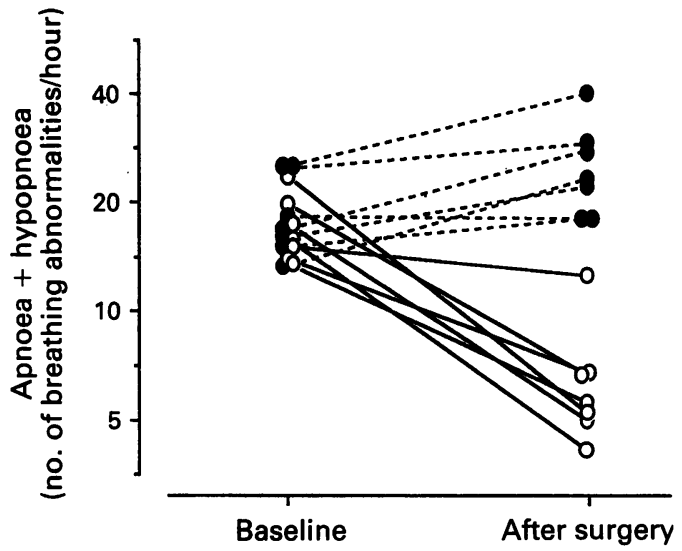

Figure 2 Individual values of the apnoea + hypopnoea index obtained at baseline and after surgery. Open circles represent patients with normal $P A S$ and $M P-H$ values, and black circles those with abnormal values of these parameters.

\section{Discussion}

Our results show that cephalometric measurements may be useful in predicting the response to nasal surgery in patients with mild SAHS who have an impediment in nasal respiration.

Measurements of PAS and MP-H distances were used to separate normal and abnormal cephalometry. This is justified since the main cephalometric abnormalities observed in SAHS are these two distances, ${ }^{15} 25$ while the other abnormalities such as the shortening and retroposition of the mandible are not constantly observed. ${ }^{25}$

Since nasal obstruction was improved in all our subjects and nasal resistance decreased in all of whom it was measured, differences in surgical efficiency on SAHS cannot be explained by differences in the improvement of nasal flow.

Our patients had mild SAHS with apnoea + hypopnoea indices of $13 \cdot 3-25 /$ hour. The frequency of respiratory disturbance is correlated with the extent of cephalometric abnormalities in non-obese patients with sleep apnoea. Even though the night to night variability of breathing disorders is greater in patients with infrequent sleep apnoea, ${ }^{26}$ it is unlikely that spontaneous variations could account for our results as the effectiveness of nasal surgery was related to the results of cephalometry and not to the severity of sleep related breathing abnormalities. Although our patients had mild SAHS, we believe treatment was justified. The repercussions of SAHS not only depend on the frequency of apnoea hypopnoea, its duration, or related desaturations, but also on sleep fragmentation. ${ }^{27}$ The improvement in arousal index seen in those patients who benefited from nasal surgery justified this approach.

Sleep induced breathing disorders were corrected in all but one patient with normal PAS and MP-H distances. The reason for the ineffectiveness of nasal surgery in one patient is unclear; he had no other cephalometric abnormalities and his nasal resistance decreased significantly with surgery (from 3.2 to 
$\left.1.6 \mathrm{~cm} \mathrm{H} \mathrm{H}_{2} \mathrm{O} / 1 / \mathrm{s}\right)$. It is possible that other soft tissue abnormalities were missed by conventional cephalometry, or that he had an increased upper airways collapsibility, or both.

Previous reports suggest that the effectiveness of surgical correction of nasal obstruction depends on age: sleep related breathing disorders are frequently reversible after nasal surgery in children ${ }^{11} 28$ while surgery is rarely useful in adults. ${ }^{8-11}$ In adults with allergic rhinitis, however, the sleep related breathing disorders associated with transient nasal obstruction are reversible when nasal resistance decreases. ${ }^{7}$ These differences in the effects of relieving impediment to nasal airflow could be related to the consequences of chronic nasal obstruction. Miller et al reported that nasal obstruction in young rhesus monkeys altered the tonic and phasic neuromuscular activity of upper airway, mandibular, and facial muscles. ${ }^{29}$ These changes in muscular activities could explain the changes in mandibular growth observed in these animals. ${ }^{3031}$ Since pharyngeal configuration depends on anatomical bony structures, ${ }^{32}$ chronic nasal airflow limitation may lead to neuromuscular and craniomandibular abnormalities in man. These acquired abnormalities could by themselves compromise the stability of the upper airway, accounting for the persistence of sleep related breathing abnormalities after late relief of nasal obstruction. It is possible that in our patients the time course of nasal obstruction differed between those with and those without abnormal cephalometric measurements. The retrospective evaluation of nasal symptoms would not be reliable in identifying such a difference. If this hypothesis is true early treatment of nasal abnormalities, possibly in infancy, may prevent the subsequent development of SAHS in adults.

We conclude that the correction of nasal flow limitation may be an effective treatment of mild SAHS in patients with nasal obstruction and no craniomandibular abnormalities.

This work was supported by The Respiratory Health Network of Centres of Excellence of Canada.

1 Remmers JE, De Groot WJ, Sauerland EK, Anch AM Pathogenesis of upper airway occlusion during sleep. $\mathcal{f}$ Appl Physiol 1978;44:931-8.

2 Onal E, Leech JA, Lopata M. Dynamics of respiratory drive and pressure during NREM sleep in patients with occlusive sleep apneas. F Appl Physiol 1985;58:1971-4.

3 Issa FG, Sullivan CE. Upper airway closing pressures in obstructive sleep apnea. $\mathcal{F}$ Appl Physiol 1984;57:520-7.

4 Gleadhill IC, Schwartz AR, Scubert N, Wise RA, Permutt S, Smith P. Upper airway collapsibility in snorers and in patients with obstructive hypopnea and apnea. $A m$ Rev Respir Dis 1991;143:1300-3.

5 Zwillich CW, Pickett C, Hanson FN, Weil JV. Disturbed sleep and prolonged apnea during nasal obstruction in normal men. Am Rev Respir Dis 1981;124:158-60.

6 McNicholas WT, Tarlo S, Colle P, Zamel N, Rutherford $\mathrm{R}$, Griffin $\mathrm{D}$, et al. Obstructive apneas during sleep in patients with seasonal allergic rhinitis. Am Rev Respir Dis 1982;126:625-8.

7 Leznoff A, Haight JS, Hoffstein V. Reversible obstructive sleep apnea caused by occupational exposure to guar gum dust. Am Rev Respir Dis 1986;133:935-6.

8 Heimer D, Scharf SM, Lieberman A, Lavie P. Sleep apnea syndrome treated by repair of deviated nasal septum. Chest 1983;84:184-5.

9 Simmons FB, Guilleminault C, Dement WC, Tilkian AG, Hill $M$. Surgical management of airway obstruction during sleep. Laryngoscope 1977;87:326-38.

10 Rubin AHE, Eliaschar I, PJoachim Z, Alroy G, Lavie P. Effects of nasal surgery and tonsillectomy on sleep apnea. Bull Eur Physiopathol Respir 1983;19:612-15.

11 Aubert-Tulkens G, Hamoir M, Van Den Eeckault J Rodenstein DO. Failure of tonsil and nose surgery in adults with long standing severe sleep apnea syndrome. Arch Intern Med 1989;149:2118-21.

12 Suratt PM, Dee P, Atkinson RL, Armstrong P, Wilhoit SC. Fluoroscopic and computed tomographic features of the pharyngeal airway in obstructive sleep apnea. $A m$ Rev Respir Dis 1983;127:487-92.

13 Rivlin J, Hoffstein V, Kalbfleisch J, McNicholas W, Zamel $\mathrm{N}$, Bryan AC. Upper airway morphology in patients with idiopathic obstructive sleep apnea. Am Rev Respir Dis 1984;129:355-60.

14 Rodenstein DO, Dooms G, Thomas Y, Liistro G, Stanescu DC, Culée C, et al. Pharyngeal shape and dimensions in healthy subjects, snorers, and patients with obstructive sleep apnoea. Thorax 1990;45:722-7.

15 Partinen M, Guilleminault C, Quera-Salva MA, Jamieson A. Obstructive sleep apnea and cephalometric roentgenograms. Chest 1988;93:1199-205.

16 Maltais F, Sériès F, Carrier G, Cormier Y. Cephalometric measurements in snorers, non-snorers and sleep apnea patients. Thorax 1991;46:419-23.

17 Riley R, Guilleminault C, Powell N, Simmons FB. Palatopharyngoplasty failure, cephalometric roentgenograms, and obstructive sleep apnea. Otolaryngol Head Neck Surg 1985;93:240-4.

18 Sériès F, St Pierre S, Carrier G. Effects of surgical correction of nasal obstruction in the treatment of obstructive sleep apnea. Am Rev Respir Dis 1992;146:1261-5.

19 Chadha TS, Watson H, Birch S, Jenouri GA, Schneider AW, Cohn MA, et al. Validation of respiratory inductive plethysmography using different calibration procedures. Am Rev Respir Dis 1982;125:644-9.

20 Rechtschaffen A, Kales A, eds. A manual of standardized terminology and scoring system for sleep stages of human subjects. Los Angeles: Brain Information Service/Brain Research Institute, University of California at Los Angeles, 1968.

21 American Sleep Disorders Association. EEG arousals: scoring rules and examples. Sleep 1992;15:174-83.

22 Sériès F, Cormier Y, La Forge J. Effects of respiratory drive on upper airways in sleep apnea patients and in normals. F Appl Physiol 1989;67:973-9.

23 Bean J, Kramer JR, Khouw FE. A simplified method of taking radiographs for cephalometric analysis. $f$ Oral Surg 1970;28:675-8.

24 Srivastava MS, Carter EM, eds. An introduction to applied multivariate statistics. Amsterdam: North Holland, 1983.

25 Strelzow VV, Blanks RHI, Basile A, Strelzow AE Cephalometric airway analysis in obstructive sleep apnea syndrome. Laryngoscope 1988;98:1149-58.

26 Wittig RM, Romaker A, Zorick FJ, Roehrs TA, Conway WA, Roth T. Night-to-night consistency of apneas during sleep. Am Rev Respir Dis 1984;129:244-6.

27 Guilleminault C, Partinen M, Quera-Salva MA, Haydes B, Dement WC, Nino-Murcia G. Determinants of daytime sleepiness in obstructive sleep apnea. Chest 1988;94: 32-7.

28 Brouillette RT, Fernbach SK, Hunt CE. Obstructive sleep apnea in infants and children. Pediatrics 1982;100:31-40.

29 Miller AJ, Vargervik K, Chierici G. Sequential neuromuscular changes in rhesus monkeys during the initial adaptation to oral respiration. Am f Orthod 1982;81:99-107.

30 Tomer BS, Harvold EP. Primate experiments on mandibular growth direction. Am $f$ Orthod 1982;82: 115-19.

31 Harvold EP, Tomer B, Vargevik K, Chierici G. Primate experiments on oral respiration. Am $f$ Orthod 1981; 79:359-72.

32 Reed WR, Roberts JL, Thach BT. Factors influencing regional patency and configuration of the human infant upper airway. F Appl Physiol 1985;58:635-44. 